\title{
Colorectal cancer complicating Crohn's disease
}

\author{
Hugh J Freeman MD
}

HJ Freeman. Colorectal cancer complicating Crohn's disease. Can J Gastroenterol 2001;15(4):231-236. Some earlier studies have indicated that patients with inflammatory bowel disease, especially those with long-standing and extensive ulcerative colitis, have an increased risk of colorectal cancer. Moreover, others in tertiary care centres have suggested that patients with Crohn's disease also have a higher risk of colorectal cancer. Canadian data on colorectal cancer in Crohn's disease appear to be limited. For this investigation, a single clinician database of 877 patients with Crohn's disease was used. Altogether, there were six patients with colorectal cancer (ie, overall rate of $0.7 \%$ ). All of these patients were men with an initial diagnosis of Crohn's disease established at a mean age of approximately 28 years, with either ileocolonic disease or colonic disease alone, but not with ileal disease alone. Although there was a predominance of women in the overall study population (ie, 56.1\%), no women developed colorectal cancer. The clinical behaviour of Crohn's disease was classified as nonstricturing in all six patients with colorectal cancer, but in two patients, Crohn's disease was complicated by a perirectal abscess or a fistula. All cancers were located in the rectum and were diagnosed 30 years, 22 years, seven years, 18 years, 20 years and 40 years after Crohn's disease was initially diagnosed. In three patients, the cancer was detected in a residual rectal stump after a partial colon resection at least 10 years earlier. In five patients, localized extension of disease through the serosa, nodal or dis- tant metastases (ie, liver, lung) was found at the time of cancer diagnosis; two patients have since died. The present study confirms that Crohn's disease involving the colon may be a possible risk factor for the development of colorectal cancer, at least in younger men, but, in this study, not in women. However, part of this increased risk in men may have been related to the presence of a rectal stump, rather than to Crohn's disease per se.

Key Words: Colon cancer; Crohn's disease; Inflammatory bowel disease; Rectal cancer; Rectal stump cancer

\section{Cancer colorectal - Complication de la maladie de Crohn}

RÉSUMÉ : Certaines études antérieures ont mentionné que des patients atteints de maladie inflammatoire de l'intestin, particulièrement s'ils souffraient de colite ulcéreuse étendue de longue date, étaient exposés à un risque accru à l'égard du cancer colorectal. De plus, d'autres études provenant de centres de soins tertiaires, ont aussi évoqué le fait que les patients atteints de maladie de Crohn étaient exposés à un risque plus élevé de cancer colorectal. Les données canadiennes sur le cancer colorectal dans la maladie de Crohn semblent limitées. Pour cette recherche, la base de données d'un seul médecin comptant 877 patients atteints de maladie de Crohn a été utilisée. Dans l'ensemble, on a

voir page suivante

Department of Medicine (Gastroenterology), University of British Columbia, Vancouver, British Columbia

Correspondence and reprints: Dr Hugh Freeman, ACU F-137, University of British Columbia Hospital (Gastroenterology),

2211 Wesbrook Mall, Vancouver, British Columbia V6T 1W5. Telephone 604-822-7216, fax 604-822-7236

Received for publication March 29, 1999. Accepted June 8, 1999 
dénombré six patients atteints d'un cancer colorectal (c'est-à-dire taux global de 0,7\%). Tous ces patients étaient des hommes dont le diagnostic initial de maladie de Crohn avait été posé à l'âge moyen d'environ 28 ans et qui souffraient soit de maladie iléo-colique ou de maladie colique seulement, mais non de maladie iléale seulement. Bien qu'on ait noté une prédominance des femmes dans la population globale de l'étude (c.-à-d. 56,1\%), aucune femme n'a développé de cancer colorectal. L'évolution clinique de la maladie de Crohn a été jugée sans strictures chez les six patients atteints de cancer colorectal, mais chez deux d'entre eux, la maladie de Crohn s'est compliquée d'abcès périrectaux ou d'une fistule. Tous les cancers ont été localisés au rectum et ont été diagnostiqués $30,22,7,18,20$ et 40 ans après le diagnostic initial de maladie de
Crohn. Chez trois patients, le cancer a été décelé dans un moignon rectal résiduel après une résection partielle du côlon effectuée au moins dix ans auparavant. Chez cinq patients, on a découvert au moment du diagnostic de cancer, une extension localisée de la maladie par la séreuse, sous la forme de métastases ganglionnaires ou distantes (p. ex., foie, poumons). Deux patients sont décédés depuis lors. La présente étude confirme que la maladie de Crohn affectant le côlon peut être un facteur de risque possible à l'égard du développement du cancer colorectal, du moins chez les hommes jeunes, mais non chez les femmes. Par contre, une partie de l'accroissement du risque chez l'homme peut avoir trait à la présence d'un moignon rectal plutôt qu'à la maladie de Crohn ellemême.
$\mathrm{P}$ rior studies have established that patients with inflammatory bowel disease, especially those with extensive and long-standing ulcerative colitis, have an increased risk of subsequent colorectal cancer (1-5). These studies of ulcerative colitis, however, have been based on data from tertiary care settings, primarily in the United States and the United Kingdom. Others practising in similar geographic areas, particularly in the United States, have shown that the magnitude of risk may not be significant $(6,7)$, while some have argued that the risk of cancer is not increased in patients with colitis (8). A number of studies have also suggested that patients with Crohn's disease have an increased risk of colorectal cancer (9-11). In Canada, some have assumed that the risk of cancer in patients with ulcerative colitis or Crohn's disease is similar to that observed in American centres, but, to date, there have been no published studies from Canada.

The present report describes an experience with colorectal cancer using a single clinician database, developed during a 20-year period, in 877 patients with Crohn's disease in a tertiary care teaching hospital setting. The results of this study indicate that colorectal cancer may complicate the clinical course of Crohn's disease, particularly in younger men with long-standing disease, but part of this increased risk may be due to possible factors associated with the presence of a residual rectal stump rather than to Crohn's disease per se.

\section{CASE PRESENTATIONS}

Case 1: A 59-year-old man was diagnosed with rectal cancer in 1995 . He was initially evaluated for bloody diarrhea in 1965. At that time, sigmoidoscopy, rectal biopsy and barium enema revealed Crohn's disease involving the sigmoid colon with a normal rectum, and he received sulphasalazine until 1985. He was first evaluated at the University of British Columbia, Vancouver, British Columbia, in April 1989 for recurrent diarrhea. Colonoscopy showed segmental inflammatory changes from 40 to $60 \mathrm{~cm}$ proximal to the anal verge. The distal colorectum was completely normal. Upper gastrointestinal endoscopy revealed focal inflammatory changes in the gastric antrum and duodenum without granulomas. Tests for Helicobacter pylori were negative. Treatment with 5-aminosalicylate (Asacol, Proctor \& Gamble Pharmaceuticals, Canada) was associated with resolution of symptoms. In 1993, repeat endoscopic studies of his upper and lower gastrointestinal tracts were normal, but a rectal biopsy showed focal inflammatory change with no dysplasia. In 1995, recurrent rectal bleeding occurred. Rectal examination revealed a palpable nodule. Sigmoidoscopy and biopsy confirmed the presence of an adenocarcinoma. Abdominoperineal resection revealed metastatic adenocarcinoma in two of five lymph nodes. By October 1995, radiation therapy and adjuvant chemotherapy with 5-fluorouracil were completed. Since 1995, he has remained well on 5-aminosalicylate alone, with no evidence of recurrent neoplastic disease.

Case 2: A 46-year-old man was diagnosed with rectal stump cancer in 1990. Crohn's disease was first diagnosed in 1968 in Montreal, Quebec during a laparotomy for clinically suspected appendicitis. An ileocecal resection was done. In 1980, recurrent ileal disease was defined, and an ileosigmoid fistula was present. An intra-abdominal abscess was surgically drained, and additional small bowel and colon were resected. A rectal stump was created. In 1986, an anal fistula was diagnosed, and azathioprine was administered for almost one year, with apparent resolution of the anal disease. In 1986, he moved to Vancouver and was initially seen in 1990. Physical examination revealed a focal indurated area at the anal verge suggestive of a small perianal abscess. Results of a flexible sigmoidoscopy and rectal biopsy were normal. Treatment with metronidazole $1000 \mathrm{mg}$ daily was provided but, due to persistent perianal symptoms and development of fever, he was hospitalized. A horseshoe-shaped posterior perirectal abscess was drained, but biopsy showed a mucinous rectal adenocarcinoma. Abdominoperineal resection was done; an infiltrating adenocarcinoma was present with one of four lymph nodes positive for metastatic disease. He received radiation therapy, and results of a subsequent endoscopic evaluation through his colostomy, with biopsies, were normal. In 1992, pulmonary metastases were initially detected. Chemotherapy with 5-fluorouracil and leucovorin failed to prevent recurrent pelvic disease and enlarging pulmonary lesions, with subsequent death.

Case 3: A 29-year-old man first developed diarrhea in 1983 and, after barium radiographs in Victoria, British Columbia, Crohn's disease of the colon was diagnosed. He was treated with sulphasalazine and corticosteroid enemas. Symptoms initially resolved but then promptly recurred with weight 
loss. Colonoscopy confirmed the presence of extensive and deep ulcerations with rectal and cecal sparing; colonic biopsies showed inflammatory changes but no granulomas or dysplasia. Results of ileal biopsies were normal. He was treated with parenteral nutrition and intravenous corticosteroids. In April 1987, he declined surgical treatment, and a course of prednisone was completed by June 1987. He was referred for a second opinion in 1987; surgical treatment was again declined. He was followed-up elsewhere, where he was administered repeated blood transfusions for anemia. In December 1990, he developed an acute abdomen while playing football. Laparotomy showed a perforated rectosigmoid carcinoma with generalized peritonitis; biopsies confirmed the presence of a poorly differentiated adenocarcinoma involving the liver, with multiple nodules. Extensive bilateral bronchopneumonia developed, followed by death, and an autopsy confirmed the presence of advanced colorectal cancer with extensive hepatic metastases.

Case 4: A 48-year-old man was diagnosed with rectal stump cancer in 1985 . He had a subtotal colectomy for presumed ulcerative colitis in 1967. Later in the same year, he developed a peristomal abscess with a fistula to the ileum requiring terminal ileum resection and repositioning of his ileostomy; the resected ileum showed granulomatous inflammation, consistent with Crohn's disease. In 1985, purulent rectal stump drainage was first observed, leading to rectal stump excision; a well differentiated rectal carcinoma was present. No lymph nodes were involved, but local involvement of the proximal muscle margin was detected. Following the rectal stump excision, he had pelvic radiation. His perineal wound healed poorly with persistent drainage. Treatment with metronidazole $1000 \mathrm{mg}$ daily had no definite effect on the drainage. He was referred to the University of British Columbia in 1987 because of a chronic deep perineal wound and scrotal fistula; the wound was debrided and the fistula excised. From July 1987 to December 1987, he had repeated surgical debridements with excision of the perineal skin. By July 1988, the perineal skin had completely healed.

Case 5: A 28-year-old man initially noticed bleeding from his rectum in 1965. A sigmoidoscopic examination showed segmental inflammatory changes, and 'colitis' was diagnosed; he was treated with sulphasalazine. Symptoms resolved after 14 months, and medications were discontinued.

In 1985, bloody diarrhea recurred; results of fecal cultures and parasite studies were negative. Sulphasalazine was associated with symptom resolution, then recurrence. Colonoscopy showed segmental mucosal inflammatory changes with focal aphthoid and serpiginous ulcers; biopsies showed granulomatous inflammation consistent with Crohn's disease. In addition, a localized rectal cancer was detected. Low anterior resection showed that the tumour had infiltrated the serosa. Subsequent sulphasalazine treatment was associated with resolution of his diarrhea. Results of a colonoscopy in 1987 were normal, except for the presence of a few scattered aphthoid ulcers; results of biopsies
TABLE 1

Characteristics of Crohn's disease in six men with colon cancer

\begin{tabular}{|c|c|c|c|c|}
\hline $\begin{array}{l}\text { Case (age at } \\
\text { diagnosis*) }\end{array}$ & $\begin{array}{c}\text { Year of } \\
\text { diagnosis* }\end{array}$ & $\begin{array}{l}\text { Site of } \\
\text { disease }\end{array}$ & Behaviour & Treatment \\
\hline 1 (29 years) & 1965 & Colon only & NS/NP & SP/5-ASA \\
\hline 2 (24 years) & 1968 & Ileum and colon & Penet & $\begin{array}{l}\mathrm{SP} / 5-\mathrm{ASA} / \mathrm{Aza} / \\
\text { ileocolic } \\
\text { resections (2) }\end{array}$ \\
\hline 3 (29 years) & 1983 & Colon only & Penet & SP/steroids/TPN \\
\hline 4 (30 years) & 1967 & Ileum and colon & Penet & $\begin{array}{l}\text { Subtotal colectomy, } \\
\text { ileocolic } \\
\text { resection }(1)\end{array}$ \\
\hline 5 (30 years) & 1965 & Colon only & NS/NP & SP \\
\hline 6 (24 years) & 1958 & Colon only & Penet & $\begin{array}{c}\text { Aza/steroids/partial } \\
\text { colectomy }\end{array}$ \\
\hline
\end{tabular}

*Diagnosis of Crohn's disease. 5-ASA 5-Aminosalicylate; Aza Azathioprine; NS/NP Nonstricturing and nonpenetrating; Penet Penetrating, perforating or fistulizing; SP Sulphasalazine; TPN Total parenteral nutrition

from uninvolved colonic mucosa were normal. Results of laboratory tests, including liver chemistry tests and carcinoembryonic antigen, as well as abdominal-pelvic ultrasound studies, were normal.

Case 6: A 64-year-old male physician developed rectal stump cancer in 1998. 'Colitis' was diagnosed in 1958, and a subtotal colectomy was done. An ileostomy was created with a rectal stump. He remained well until 1988, when he was hospitalized for a clinical diagnosis of a bowel obstruction. He was reluctant to have any further surgical treatment. Over the past five years, sigmoidoscopic examinations of a rectal stump revealed some inflammatory changes; there were no granulomas. He was treated with azathioprine, intermittent prednisone and corticosteroid enemas. In 1998, a fistulous tract developed from the apex of the rectal stump to the small bowel, and mucosal biopsies from the rectal stump showed focal dysplastic change. He was referred for a second opinion in 1998. Examination revealed an anorectal stricture, but a flexible sigmoidoscopy showed a diffusely hyperemic and friable rectal mucosa. Biopsies showed dysplastic colonic mucosal changes with invasive rectal carcinoma. An abdominoperineal resection was done, with removal of the rectal stump and fistulous tract. Pathological evaluation showed an infiltrating, moderately differentiated adenocarcinoma extending into the subserosal mesentery; changes of Crohn's disease with fissuring ulceration and subserosal abscess formation; and an unexpected focal squamous cell carcinoma at the anorectal junction. Lymph nodes in the resected specimen were negative for any metastatic neoplasm. Subsequently, radiation treatment and a course of chemotherapy were completed.

\section{RESULTS}

Patient population: A total of 877 patients with Crohn's disease were evaluated over a period of 20 years. In this group, there were 385 men $(43.9 \%)$ and 492 women 
TABLE 2

Characteristics of colon cancer in six men with Crohn's disease

\begin{tabular}{|c|c|c|c|c|c|}
\hline $\begin{array}{l}\text { Case (age at } \\
\text { diagnosis*) }\end{array}$ & $\begin{array}{c}\text { Year of } \\
\text { diagnosis* }\end{array}$ & Duration $^{\dagger}$ (years) & $\begin{array}{l}\text { Location/ } \\
\text { Metastatic disease }\end{array}$ & Type & Treatment \\
\hline 1 (59 years) & 1995 & 30 & Rectum/nodes & Adenocarcinoma & $\begin{array}{c}\text { Abdominoperineal resection/ } \\
\text { radiation therapy/ } \\
\text { chemotherapy }\end{array}$ \\
\hline 2 (46 years) & 1990 (deceased 1992) & 22 & Rectal stump/nodes and lungs & $\begin{array}{c}\text { Mucinous } \\
\text { adenocarcinoma }\end{array}$ & $\begin{array}{l}\text { Abdominoperineal resection/ } \\
\text { radiation therapy/ } \\
\text { chemotherapy }\end{array}$ \\
\hline 3 (36 years) & 1990 (deceased 1990) & 7 & Rectum (perforated)/Liver & Adenocarcinoma & None (see text) \\
\hline 4 (48 years) & 1985 & 18 & Rectal stump only ${ }^{\ddagger}$ & Adenocarcinoma & $\begin{array}{l}\text { Abdominoperineal resection/ } \\
\text { radiation therapy }\end{array}$ \\
\hline 5 (50 years) & 1986 & 20 & Rectum only & Adenocarcinoma & Lower anterior resection \\
\hline 6 (54 years) & 1998 & 40 & Rectal stump only ${ }^{\ddagger}$ & $\begin{array}{c}\text { Adenocarcinoma } \\
\text { and incidental squamous } \\
\text { cell carcinoma }\end{array}$ & $\begin{array}{l}\text { Abdominoperineal resection/ } \\
\text { radiation therapy/ } \\
\text { chemotherapy }\end{array}$ \\
\hline
\end{tabular}

${ }^{*}$ Diagnosis of colon cancer; ${ }^{\dagger}$ Duration of Crohn's disease before detection of colon cancer; ${ }^{\ddagger}$ Localized extension beyond serosa but no nodal involvement

(56.1\%). Of the 877 patients, $42 \%$ had their diagnosis first established between the ages of 20 and 29 years. Other details related to this patient population have been described elsewhere, including patient age and sex distribution, site of disease involvement and clinical behaviour of the Crohn's disease (12). The mean follow-up period for the total patient group was 7.8 years. For the six men with Crohn's disease described in the present report who developed colorectal cancer, Table 1 details the age and year of diagnosis of the Crohn's disease, site of disease, clinical behaviour (penetrating or stricturing), and the pharmacological and/or surgical treatment received. The mean age at diagnosis of the patients with Crohn's disease who developed colorectal cancer was higher than the mean age of this Crohn's disease population. All six had colonic involvement and, in four, only colonic disease was detected. The clinical behaviour of the Crohn's disease was classified as penetrating or perforating in four of six patients, and two patients developed a fistulous tract. Four patients required at least one surgical procedure for their Crohn's disease; of these, three had a rectal stump left in situ, each for over 10 years.

Colorectal cancer: Table 2 lists details related to the diagnosis of colorectal cancer in the six men with Crohn's disease, including the age and year of diagnosis of colorectal cancer, the estimated number of years from the diagnosis of Crohn's disease to the diagnosis of colorectal cancer, the site and location of metastatic disease, histological types of colorectal cancer and treatment received. The ages at diagnosis of colorectal cancer for this group of six men ranged from 30 years to 59 years and, for most patients, the mean estimated duration from the time of diagnosis of Crohn's disease to the time of diagnosis of colorectal cancer was over 20 years. Of these cancers, all were located in the rectum and most, at the time of diagnosis, were advanced. To date, two patients have died. Three patients had rectal stump cancer; dysplastic mucosal changes were detected in one of these patients before the diagnosis of colorectal cancer. Although an adenocarcinoma was diagnosed in all six patients, a small squamous cell cancer was also detected at the anorectal junction in the resected surgical specimen of one patient.

Other malignant diseases: Other malignancies recorded to date in the overall population of 877 patients with Crohn's disease have included two malignant melanomas (one man, one woman; both deceased), one glioblastoma (man; deceased), one atrial myxoma (man), one cervical cancer (woman), one appendiceal carcinoid (woman), one myeloma (man; deceased), two leukemia (two men; both deceased), one Hodgkin's disease (woman) and one small bowel carcinoma (woman).

\section{DISCUSSION}

Previous studies from tertiary care centres in the United States and the United Kingdom have suggested that patients with Crohn's disease have an increased risk of colorectal cancer (9-11), as well as an excess mortality attributed to digestive tract tumours (13). Weedon et al (9), at the Mayo Clinic, described colorectal cancer complicating the course of Crohn's disease in eight of 449 patients (or approximately $1.2 \%$ ), for an estimated 20 times greater risk than that of a control population. Similarly, Gyde et al (10) reported an approximately fourfold increased risk in patients with Crohn's disease from the United Kingdom. Subsequently, in a survey of 126 individual gastroenterologists from the United States, not necessarily employed in the tertiary care setting, Korelitz (14) described 54 patients with colorectal cancer from an estimated population of 16,469 patients with Crohn's disease (approximately $0.33 \%$ ), suggesting an increased risk of colorectal cancer in patients with Crohn's disease, but the magnitude of this risk was not clear. To date, specific data from Canada on col- 
orectal cancer complicating Crohn's disease are very limited. The present study evaluated a single clinician database of 877 patients from a teaching hospital setting; altogether, a total of six patients (approximately $0.68 \%$ ) with colorectal cancer complicating Crohn's disease were detected. This number approximates the increased risk of colorectal cancer reported for patients with Crohn's disease, even though the number of patients reported in these larger centre studies is smaller $(9-11,14)$. Further studies, therefore, are needed to estimate more precisely the overall experience in Canada with colorectal cancer complicating Crohn's disease because, in the present study, the findings may not be entirely representative and the follow-up period for all 877 patients (ie, mean 7.8 years) was limited.

The clinical features of patients with colorectal cancer in the present study were similar to those noted in earlier studies, including the long history of Crohn's disease, often over 20 years, predating the development of colorectal cancer; the relatively young age at the time of the colorectal cancer diagnosis compared with the more typical age of diagnosis in patients without Crohn's disease; and the apparent predilection for other histopathological types, such as mucinous adenocarcinoma (15). This study also confirmed observations of previous studies that documented the presence of cancer in bypassed segments of the small intestine and colon (15-17) in patients with Crohn's disease. Finally, this series included a patient with squamous cell carcinoma in a rectal stump - a finding previously described only in a patients with a rectal stump following surgery for ulcerative colitis rather than Crohn's disease (18).

Three of six patients with Crohn's disease involving the colon in the present series had rectal stump cancer. For each patient, surgical treatment, including creation of a rectal stump, had been done more than 10 years earlier. Others have also observed this phenomenon in patients with both ulcerative colitis and Crohn's disease $(15,19,20)$. The precise cause for these findings is not clear. Interestingly, Sachar (21) previously argued, possibly correctly, that the prolonged presence of unresected disease per se, rather than bypassed or excluded mucosa, is the principal risk factor for the development of colorectal cancer. However, others (22) have conceptualized that 'misplaced' epithelium in either ulcerative colitis or Crohn's disease of the colon is most critical for later development of malignant mucosal changes. Prior experimental animal studies have provided ample evidence that other factors should be considered in the etiopathogenesis of colorectal cancer in bypassed intestine. In carcinogen-treated animals with bypassed intestine, increased numbers of intestinal, including colorectal, cancers develop, especially in the region of anastomotic suture lines $(23,24)$. Although the problem of anastomotic recurrence after resection for colorectal cancer remains a very significant concern (25), the possible role of the anastomotic suture per se has also been explored as an independent risk factor for colorectal cancer in this experimental model (26). These studies demonstrated that slowly absorbed or nonabsorbable suture materials, such as silk, promoted local colorectal tumour development in a carcinogen-induced animal model; moreover, multifilament stainless steel suture material also enhanced tumour development at a more distal or 'downstream' site (26). Other investigators have suggested that these changes may be due, in part, to hyperplastic or proliferative changes near the colonic anastomosis in experimental carcinogenesis (27) or in more distal rectal mucosa after jejunoileal bypass for morbid obesity (28). Further studies to elucidate factors that might promote the development of colorectal cancer in the bypassed rectal stump mucosa of patients with inflammatory bowel disease are needed. Nevertheless, part of the increased risk of colorectal cancer in the patients with Crohn's disease in the present study may have been related to the presence of a rectal stump, rather than to Crohn's disease per se.

In spite of the findings of the present study, it would be inappropriate to make any meaningful recommendations for surveillance programs in patients with Crohn's disease, especially because the mean duration of follow-up in this single clinician practice experience was limited and was not uniform. Moreover, in this series of patients, cancer was accompanied by, but not preceded by, confirmed dysplastic mucosal changes in only one patient. Therefore, strong recommendations for any specific program of periodic or systematic surveillance to detect dysplasia or early carcinoma cannot be provided on the basis of the present investigation. However, it still seems prudent to follow these patients with Crohn's disease closely, with periodic endoscopic biopsy evaluation, especially in those with a surgically created rectal stump. More refined studies to define the precise role of surveillance programs in this subset of patients with Crohn's disease are still needed.

\section{REFERENCES}

1. Devroede GJ, Taylor WF, Sauer WG, Jackman RJ, Stickler GB. Cancer risk and life expectancy in children with ulcerative colitis. N Engl J Med 1971;285:17-21.

2. Greenstein AJ, Sachar DB, Smith H, et al. Cancer in universal and left-sided ulcerative colitis: factors in determining risk. Gastroenterology 1979;77:290-4.

3. Kewenter J, Ahlman H, Hulten L. Cancer risk in extensive colitis. Ann Surg 1978;188:824-7.

4. Prior P, Gyde SN, MacCartney JC, Thompson H, Waterhouse JAH, Allan RN. Cancer morbidity in ulcerative colitis. Gut 1982;23:490-7.

5. Freeman HJ. Neoplastic complications of inflammatory bowel disease. In: Freeman HJ, ed. Inflammatory Bowel Disease, vol 2. Baton Raton: CRC Press, 1988:23-35.

6. Katzka I, Brody RS, Morris E, Katz S. Assessment of colorectal cancer risk in patients with ulcerative colitis: experience from a private practice. Gastroenterology 1983;85:22-9.

7. Stonnington CM, Phillips SF, Zinsmeister AR, Melton LJ. Prognosis of chronic ulcerative colitis in a community. Gut 1987;28:1261-6.

8. Gilat T, Zemishlany Z, Ribak J, Benaroya Y, Lilos P. Ulcerative colitis in the Jewish population of Tel-Aviv Yako. II. The rarity of malignant degeneration. Gastroenterology 1974;67:933-8.

9. Weedon DD, Shorter RG, Ilstrup DM, Huizenga KA, Taylor WF. Crohn's disease and cancer. N Engl J Med 1973;289:1099-103.

10. Gyde SN, Prior P, MacCartney JC, Thompson H, Waterhouse JAH, Allan RN. Malignancy in Crohn's disease. Gut 1980;21:1024-9.

11. Gillen CD, Walmsley RS, Prior P, Andrews HA, Allan RN. Ulcerative colitis and Crohn's disease: a comparison of the colorectal cancer risk in extensive colitis. Gut 1994;35:1590-2 
12. Freeman HJ. Application of the Vienna Classification for Crohn's disease to a single clinician database of 877 patients. Can J Gastroenterol. (In press)

13. Prior P, Gyde S, Cooke WT, Waterhouse JAH, Allan RN. Mortality in Crohn's disease. Gastroenterology 1981;80:307-12.

14. Korelitz BI. Carcinoma of the intestinal tract in Crohn's disease: results of a survey conducted by the National Foundation for Ileitis and Colitis. Am J Gastroenterol 1983;78:44-6.

15. Hamilton SR. Colorectal carcinoma in patients with Crohn's disease. Gastroenterology 1985;89:398-407.

16. Greenstein AJ, Sachar D, Pucillo A, et al. Cancer in Crohn's disease after diversionary surgery. A report of seven carcinomas occurring excluded bowel. Am J Med 1978;135:86-90.

17. Traube J, Simpson S, Riddell RH, Levin B, Kirsner JB. Crohn's disease and adenocarcinoma of the bowel. Dig Dis Sci 1980;25:939-44.

18. Mir-Madjlessi SH, Farmer RG. Squamous cell carcinoma of the rectal stump in a patient with ulcerative colitis. Cleve Clin Q 1985;52:257-61.

19. Kurtz LM, Flint GW, Platt N, Wise L. Carcinoma in the retained rectum after colectomy for ulcerative colitis. Dis Colon Rect 1980;23:346-50.

20. Lavery IC, Jagelman DG. Cancer in the excluded rectum following surgery for inflammatory bowel disease. Dis Colon Rectum 1982;25:522-4.
21. Sachar DB. Cancer in Crohn's disease: dispelling the myths. Gut 1994;35:1507-8.

22. Allen DC, Biggart JD. Misplaced epithelium in ulcerative colitis and Crohn's disease of the colon and its relationship to malignant mucosal changes. Histopathology 1986;10:37-52.

23. Williamson RCN, Davies PW, Bristol JB, Wells M. Intestinal adaptation and experimental carcinogenesis after partial colectomy. Increased tumor yields are confined to the anastomosis. Gut 1982;23:316-25.

24. Scudamore $\mathrm{CH}$, Freeman HJ. Effects of small bowel transection, resection or bypass in 1,2-dimethylhydrazine-induced rat intestinal neoplasia. Gastroenterology 1983;84:725-31.

25. Kieghley MRB, Hall C. Anastomotic recurrence of colorectal cancera biological phenomenon or an avoidable calamity? Gut 1987;28:786-91.

26. Calderisi RN, Freeman HJ. Differential effects of surgical suture materials in 1,2-dimethylhydrazine-induced rat intestinal neoplasia. Cancer Res 1984;44:2827-30.

27. Roe R, Fermor B, Williamson RCN. Proliferative instability and experimental carcinogenesis at colonic anastomoses. Gut 1987;28:808-15.

28. Appleton GVN, Wheeler EE, Al-Mufti R, Challacombe DN, Williamson RCN. Rectal hyperplasia after jejunoileal bypass for morbid obesity. Gut 1988;29:1544-8. 


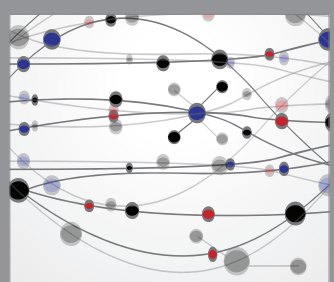

The Scientific World Journal
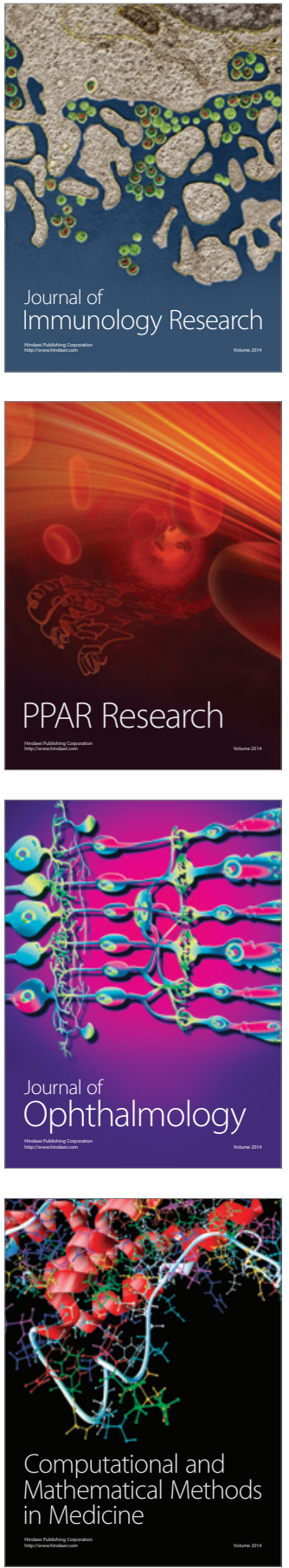

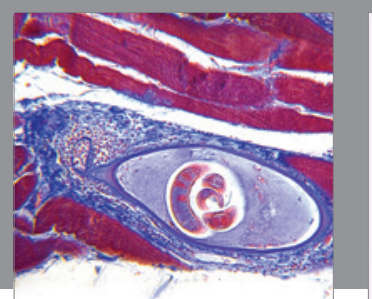

Gastroenterology Research and Practice

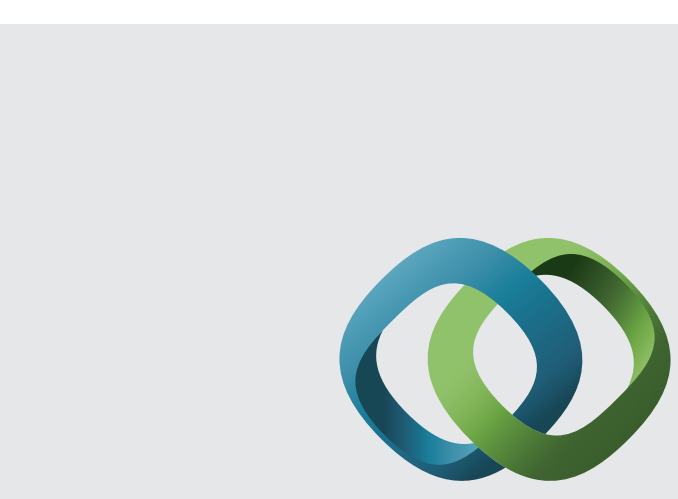

\section{Hindawi}

Submit your manuscripts at

http://www.hindawi.com
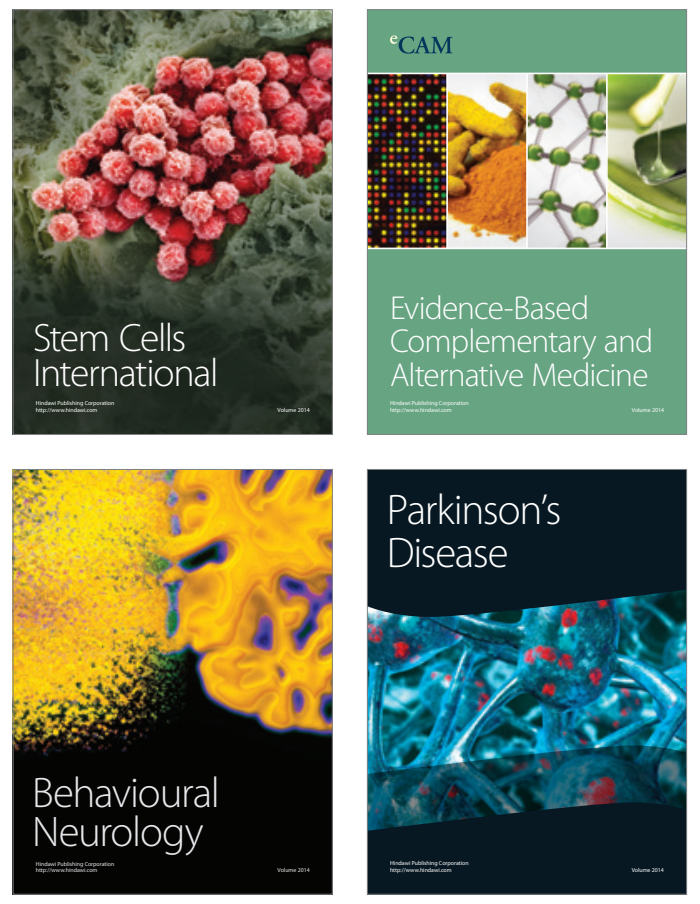
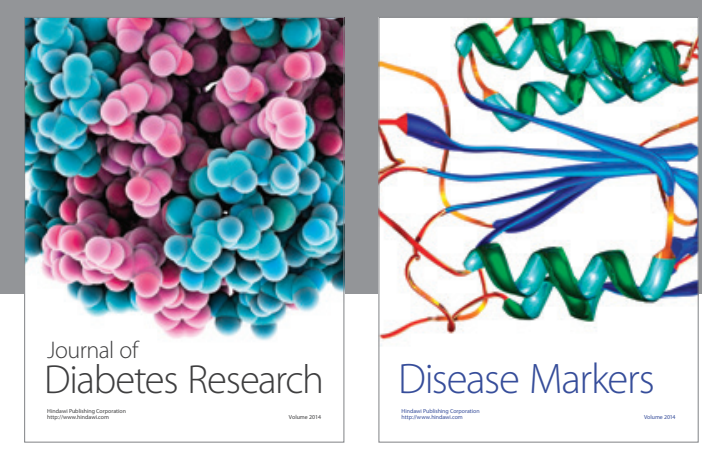

Disease Markers
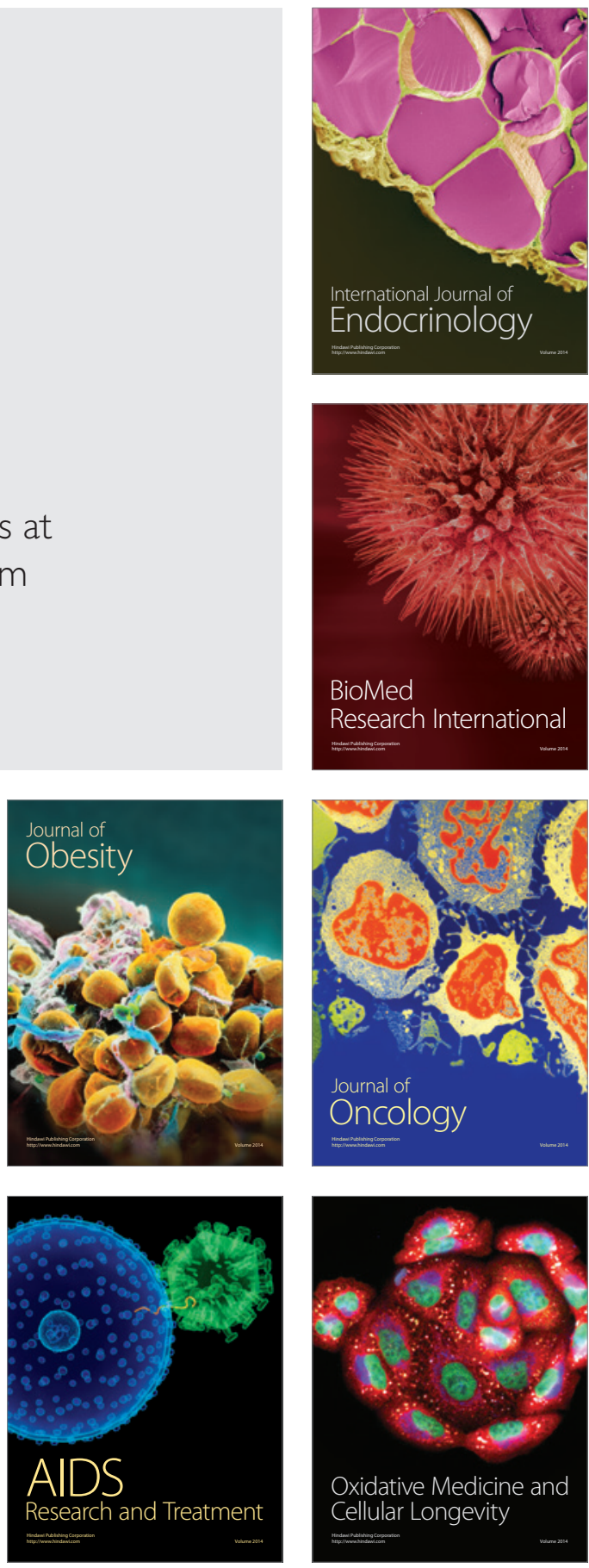